\title{
Decomposition of wind speed fluctuations at different time scales
}

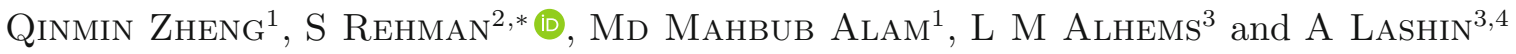 \\ ${ }^{1}$ Harbin Institute of Technology, Shenzhen Graduate School, Shenzhen, China. \\ ${ }^{2}$ Center for Engineering Research, Research Institute, King Fahd University of Petroleum and Minerals, \\ Dhahran-31261, Saudi Arabia. \\ ${ }^{3}$ College of Engineering, Petroleum and Natural Gas Engineering Department, King Saud University, Riyadh, \\ Saudi Arabia. \\ ${ }^{4}$ Department of Geology, Benha University, P.O. Box 13518, Benha, Egypt. \\ ${ }^{*}$ Corresponding author.e-mail: srehman@kfupm.edu.sa
}

\begin{abstract}
Understanding the inherent features of wind speed (variability on different time scales) has become critical for assured wind power availability, grid stability, and effective power management. The study utilizes the wavelet, autocorrelation, and FFT (fast Fourier transform) techniques to analyze and assimilate the fluctuating nature of wind speed data collected over a period of 29-42 years at different locations in the Kingdom of Saudi Arabia. The analyses extracted the intrinsic features of wind speed, including the long-term mean wind speed and fluctuations at different time scales (periods), which is critical for meteorological purposes including wind power resource assessment and weather forecasting. The longterm mean wind speed varied between $1.45 \mathrm{~m} / \mathrm{s}$ at Mecca station and $3.73 \mathrm{~m} / \mathrm{s}$ at Taif. The annual variation is the largest $( \pm 0.97 \mathrm{~m} / \mathrm{s})$ at Taif and the smallest $( \pm 0.25 \mathrm{~m} / \mathrm{s})$ at Mecca. Similarly, the wind speed fluctuation with different periods was also discussed in detail. The spectral characteristics obtained using FFT reveal that Al-Baha, Najran, Taif and Wadi-Al-Dawasser having a sharp peak at a frequency $f=0.00269$ (1/day) retain a more regular annual repetition of wind speed than Bisha, KhamisMushait, Madinah, Mecca, and Sharourah. Based on the autocorrelation analysis and FFT results, the stations are divided into three groups: (i) having strong annual modulations (Al-Baha, Najran, Taif and Wadi-Al-Dawasser), (ii) having comparable annual and half-yearly modulations (Bisha, Khamis-Mushait, and Mecca) and (iii) having annual modulation moderately prominent (Madinah and Sharourah).
\end{abstract}

\section{Introduction}

Due to fast technological development, commercial acceptance, ease of operation and maintenance, and competitive cost, wind power utilization has been on the increase during the recent past years (Rehman et al. 2015). Furthermore, the exploitation and implementation of wind power projects will reduce the dependence on fossil fuels, which will essentially result in a reduction in greenhouse gas (GHG) emissions and facilitation of energy supply for isolated grids. Because of a remarkable progress in wind energy sector, the global cumulative wind power installed capacity reached 369.597 GW at the end of the year 2014 compared to 318.644 GW in 2013, an increase of 16\% (GWEC 2015). The cumulative annual global wind power installed capacities are shown in figure 1. With a cumulative installed capacity of $91.413 \mathrm{GW}$, China remained the leader in wind power industry as of

Keywords. Wind speed prediction; wavelets; fast Fourier transform; power spectrum; wind energy. 


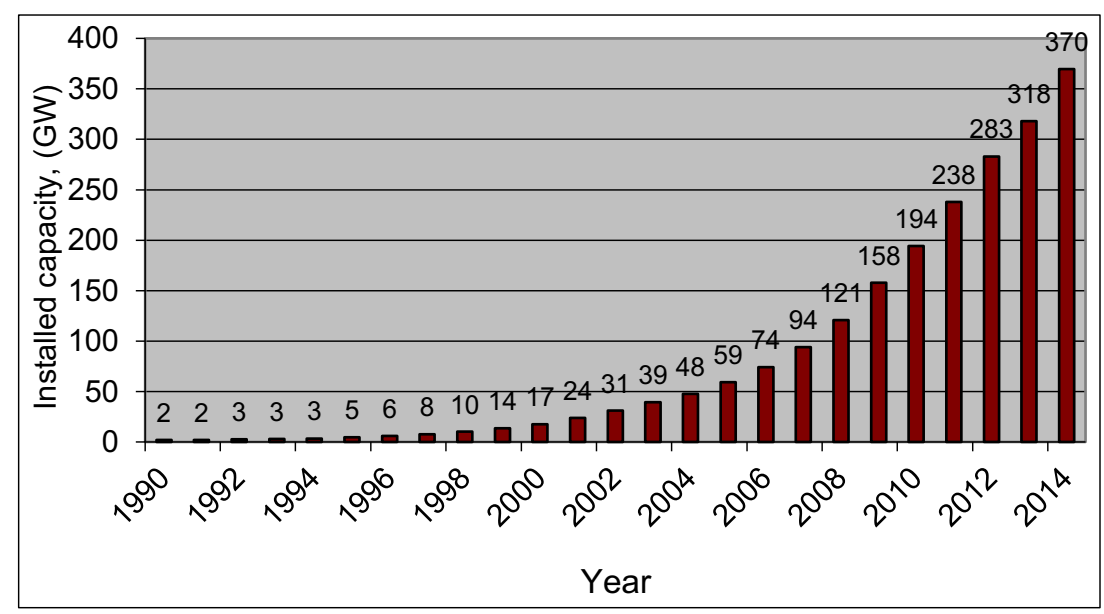

Figure 1. Global cumulative annual wind power installed growth (GWEC 2015).

December 2014. The USA, Germany, Spain and India remained at $2 \mathrm{nd}, 3 \mathrm{rd}$, 4th, and 5 th places with total cumulated wind power installed capacities of $65.879,39.165,22.987$, and $22.465 \mathrm{GW}$, respectively.

Having all facts and figures at hand, still the deployment of a profitable wind power project requires accurate wind resource assessment and dependable wind power availability over the designed life of a wind power plant. It simply means that proper understanding of the wind speed variations based on long-term historical wind data and its future trends is a pre-requisite for the success of huge investments. Hence, when planning the deployment of a wind farm at a site, an indispensable task is to conduct on-site wind speed measurements at least for one complete year (the longer the better) and analyze it to extract information on the variability of the wind (Aksoy et al. 2004; Jaramillo and Borja 2004; Akdag et al. 2010; Chang 2011; Carapellucci and Giordano 2013). The variability of wind covers a wide spectrum of timescales starting from seconds to hours, to days, to months, to a year, and to several years. Hence, we do not have the systematic understanding of wind variability and availability at very short intervals (turbulence scale), synoptic scales, seasonal variation, annual cycle variation, etc. The long-term statistical information is required not only for a feasibility study of the wind farms to be developed, but also for wind power prediction in different years/seasons/months/day, as well as wind turbine control.

The present study provides statistical information about wind speed nature for a long time in the past which is unequivocally needed for long-term wind speed predictions. Furthermore, without analytical prediction, the statistical information on the variations of past wind at different time-scales can give a rough idea about how the wind will behave in the near future (Carta et al. 2009; Garcia-Marin et al. 2013; Deane et al. 2014). Hence, for proper and optimal utilization of wind power, understanding of its characteristics in time and spatial domains has become critically essential. Short- and long-range wind forecasts over different time periods have become important requirements for the management of wind farms. To address these stated issues, wind speed characteristics have been reported worldwide using statistical, mathematical, empirical and physical time series analysis (Fourier transform, wavelet transform, detrended fluctuation analysis, artificial neural networks, Hurst exponent, autoregressive moving averages, etc.).

In recent times, the power spectral density and wavelet transform technique have been widely adopted as a useful tools to analyze measured wind speed data, in particular, and meteorological data, in general. For instance, Chellali et al. (2010) employed wavelet transform as a time-frequency analysis for the meteorological data in the region of Adrar, Algeria, to investigate the power spectra behaviors of wind speed and its variations with time. They found significant synoptic oscillations for periods of $2-16$ days in the cold weather. The wavelet power spectrum also revealed the presence of intra-seasonal oscillations for periods of 30-60 days. Alam et al. (2014) used wavelet transform and fast Fourier transform power spectrum techniques to understand the dynamic nature of the daily mean wind speed. The study found that wind speed changed by \pm 0.6 to \pm 1.6 knots over a long period of about 10 years depending on locations.

The aim of this work is to decompose the fluctuating nature of the wind speed at different time scales, extract the inherent properties of the long-term wind speed data series, and thus 
conduct detailed wind power resource assessment. Autocorrelation analysis was also performed to classify the wind speed data series. Wind power industry is competing with the conventional power systems and hence, accurate assessment of wind power resource is very helpful in assuring quality energy supply. Furthermore, the wind and other meteorological measurements are sparsely available and hence, these methods can also be used to estimate values at locations where measurements are not available.

\section{Problem definition}

The increasing integration of wind power into the grid is encouraging, but the stochastic and intermittent nature of wind power generation (Billinton et al. 1996) poses an increasing risk to the system reliability and power quality. As a result, the grid operation issues such as generation schedules and reserve allocation become matters of concern (Smith et al. 2007; Georgilakis 2008). These difficulties further complicate the possibilities of harnessing the power of the wind. In recent years, extensive efforts have been devoted towards analyzing the probability distribution and fluctuation characteristics of wind power using statistical approaches based on measured wind data. The Weibull probability density function (Carta et al. 2009; Akdağ et al. 2010; Kumar and Philip 2010; Chang 2011; Rehman et al. 2012; Bagiorgas et al. 2012) has been widely used to model the wind speed distribution on daily, monthly, seasonal or annual time scales. Usually, most of the signals contain numerous non-stationary or transitory characteristics such as drift, trends, abrupt changes, and beginnings and ends of events. These characteristics are often the most important part of the signal and are needed to be analyzed to understand physical phenomena hidden behind the signal. To study these characteristics, wavelets have been developed since the early eighties. The wavelet analysis technique allows the use of long signals where both low- and high-frequency information in the time domain is to be extracted.

\section{Site and data description}

The Kingdom of Saudi Arabia lies between latitudes $31^{\circ}-17.5^{\circ} \mathrm{N}$ and longitudes $50^{\circ}-36.6^{\circ} \mathrm{E}$. The land elevation varies between 0 and $2600 \mathrm{~m}$ above the mean sea level. Complex terrain is found in the southwest region of the Kingdom. The east and the west coasts of the Kingdom are located on the Arabian Gulf and Red Sea, respectively. Mainly, two seasons, winter and summer, are observed during the year. The historical meteorological data collected at national and international airports in the Kingdom show a long-term annual wind speed of about $4-4.5 \mathrm{~m} / \mathrm{s}$ at different locations at about $10 \mathrm{~m}$ above ground level.

The latitude, longitude, altitude, and data collection period for national and international airports are summarized in table 1 . In general, the data collection period varied from 1970 to 2013 for most of the data collection stations. At all of these stations, the hourly values of all the parameters such as wind speed (WS), wind direction (WD), dry bulb temperature ( $\mathrm{T})$, wet bulb temperature $\left(\mathrm{T}_{\mathrm{w}}\right)$, station pressure $(\mathrm{P})$, sea level pressure $\left(\mathrm{P}_{\mathrm{sl}}\right)$, relative humidity $(\mathrm{RH})$, vapour pressure $\left(\mathrm{V}_{\mathrm{p}}\right)$, total rainfall $(\mathrm{R})$, and others are recorded manually and then daily average, maximum and minimum values are computed. The technical specifications of the meteorological data collection sensors are given in table 2. The meteorological stations used in this study include Al-Baha, Bisha, Khamis Mushait, Madinah, Mecca, Najran, Sharourah, Taif, and Wadi Al-Dawasser. The geographical locations of these meteorological stations are depicted in figure 2 . The southern area has a complex terrain with high range of mountains. Abha and Khamis-Mushait are situated at $\sim 2100 \mathrm{~m}$ AMSL, while Al-Baha, Bisha and Najran at 1000-1200 m AMSL.

The long-term mean wind speed at these meteorological stations along with the total records,

Table 1. Site-specific information of meteorological stations considered in this study.

\begin{tabular}{lccccrr}
\hline Location & From & To & $\begin{array}{c}\text { Duration } \\
(\text { Years })\end{array}$ & $\begin{array}{c}\text { Latitude } \\
\left({ }^{\circ} \mathrm{N}\right)\end{array}$ & $\begin{array}{c}\text { Longitude } \\
\left({ }^{\circ} \mathrm{E}\right)\end{array}$ & $\begin{array}{c}\text { Altitude } \\
(\mathrm{m})\end{array}$ \\
\hline Al-Baha & $01 / 01 / 1985$ & $31 / 12 / 2013$ & 29 & 20.00 & 41.50 & 2155 \\
Bisha & $01 / 01 / 1972$ & $31 / 12 / 2013$ & 42 & 20.00 & 42.60 & 1166 \\
Khamis-Mushait & $01 / 01 / 1972$ & $31 / 12 / 2013$ & 42 & 18.30 & 42.80 & 1998 \\
Madinah & $01 / 01 / 1972$ & $31 / 12 / 2013$ & 42 & 24.55 & 39.72 & 646 \\
Mecca & $01 / 01 / 1985$ & $31 / 12 / 2013$ & 29 & 21.50 & 39.80 & 277 \\
Najran & $01 / 01 / 1978$ & $31 / 12 / 2013$ & 36 & 17.60 & 44.40 & 1293 \\
Sharourah & $01 / 01 / 1985$ & $31 / 12 / 2013$ & 29 & 17.50 & 47.10 & 722 \\
Taif & $01 / 01 / 1972$ & $31 / 12 / 2013$ & 42 & 21.50 & 40.60 & 1879 \\
Wadi-Al-Dawasser & $01 / 01 / 1983$ & $31 / 12 / 2013$ & 31 & 20.52 & 45.19 & 650 \\
\hline
\end{tabular}


Table 2. Technical specifications of the meteorological sensors used for measurements.

\begin{tabular}{lccllll}
\hline Sensor type & Technical & Accuracy & \multicolumn{1}{c}{ Range } & Threshold & \multicolumn{1}{c}{ Output } \\
\hline Wind speed & AC sine wave & $0.1 \mathrm{~m} / \mathrm{s}$ & $1-96 \mathrm{~m} / \mathrm{s}$ & $0.78 \mathrm{~m} / \mathrm{s}$ & $0-125 \mathrm{~Hz}$ \\
Wind direction & Mechanical & $1 \%$ & $0-360^{\circ}$ & $1^{\circ}$ & 0 -Exc. \\
Temperature & - & $\pm 1.1^{\circ} \mathrm{C}$ & $-40^{\circ} \mathrm{C}$ to $52.5^{\circ} \mathrm{C}$ & - & $0-2.5 \mathrm{~V} \mathrm{DC}$ \\
Pressure & - & $\pm 15 \mathrm{mb}$ & $150-1150 \mathrm{mb}$ & - & Linear voltage \\
\hline
\end{tabular}

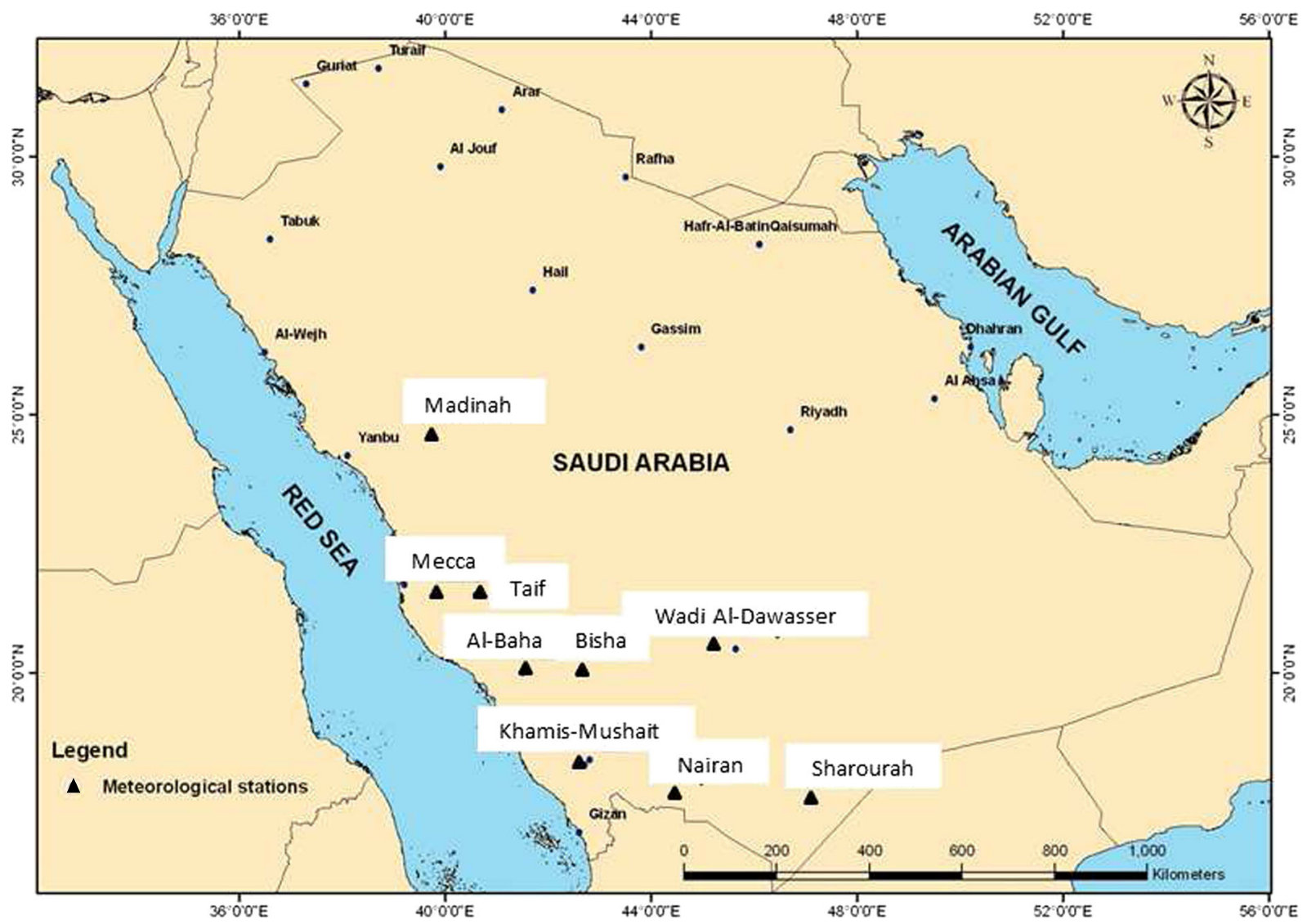

Figure 2. Location of the study area.

Table 3. Long-term statistics of daily mean wind speed.

\begin{tabular}{lccccc}
\hline Location & $\begin{array}{c}\text { Total } \\
\text { records }\end{array}$ & $\begin{array}{c}\text { Mean } \\
(\mathrm{m} / \mathrm{s})\end{array}$ & $\begin{array}{c}\text { Median } \\
(\mathrm{m} / \mathrm{s})\end{array}$ & $\begin{array}{c}\text { Max } \\
(\mathrm{m} / \mathrm{s})\end{array}$ & $\begin{array}{c}\text { Std. dev. } \\
(\mathrm{m} / \mathrm{s})\end{array}$ \\
\hline Al-Baha & 10,592 & 3.41 & 3.09 & 13.89 & 1.38 \\
Bisha & 15,334 & 2.50 & 2.57 & 12.35 & 1.15 \\
Khamis-Mushait & 15,210 & 3.00 & 2.57 & 27.78 & 1.25 \\
Madinah & 15,338 & 3.18 & 3.09 & 16.98 & 1.15 \\
Mecca & 10,592 & 1.45 & 1.54 & 17.49 & 0.77 \\
Najran & 13,149 & 2.25 & 2.06 & 11.32 & 1.10 \\
Sharourah & 10,592 & 3.32 & 3.09 & 37.55 & 1.32 \\
Taif & 15,336 & 3.73 & 3.60 & 11.32 & 1.42 \\
Wadi-Al-Dawasser & 11,262 & 3.50 & 3.09 & 13.38 & 1.55 \\
\hline
\end{tabular}

median and maximum wind speed and the corresponding standard deviations are summarized in table 3 . The data collection period varied from 29 to 42 years, as listed in table 1 . The mean wind speed was found to vary between $1.45 \mathrm{~m} / \mathrm{s}$ at
Mecca station and $3.73 \mathrm{~m} / \mathrm{s}$ at Taif with corresponding standard deviation values of 0.77 and 1.42 $\mathrm{m} / \mathrm{s}$. The maximum wind speed of $37.55 \mathrm{~m} / \mathrm{s}$ was recorded at Sharourah meteorological station while the minimum of $11.32 \mathrm{~m} / \mathrm{s}$ at Najran and Taif meteorological stations.

\section{Results and discussion}

\subsection{FFT power spectral density at different stations}

This section is devoted to the FFT analysis results of wind speed time series data recorded at nine different geographical locations, namely, AlBaha, Bisha, Khamis-Mushait, Madinah, Mecca, Najran, Sharourah, Taif and Wadi-Al-Dawasser in Saudi Arabia. The daily averaged wind speed data obtained from the above meteorological stations were recorded over varying periods from 29 to 42 
years, and the longevity of the data series has a great potential to verify the current criteria used for design practices. Here, it should be noted that the recording periods for the daily averaged wind speed are different, 29 years (1985-2013) for Al-Baha Mecca and Sharourah, 31 years (19832013) for Wadi-Al-Dawasser, 36 years (1978-2013) for Najran, and 42 years (1972-2013) for Bisha, Khamis-Mushait, Madinah and Taif. The data were recorded every hour, and daily mean values were obtained using 24 records of measured values in last $24 \mathrm{hrs}$. The total number of daily average data points in the time series for 29,31,36, and 42 yrs were 10592, 11262, 13154 and 15334, respectively, as referred in table 3 .

The power spectral density functions of the daily averaged wind speed time series data at the nine locations are shown in figure 3 , where the horizontal axis represents the frequency $f(1 /$ day $)$, and the vertical axis shows the corresponding power spectral energy.

Al-Baha is a station situated at $\sim 2155 \mathrm{~m}$ above the mean sea level in the southwest of Saudi Arabia. It is a high land having a gentle topography of $1600-1900 \mathrm{~m}$ in a radius of $200 \mathrm{~km}$. Due to the high altitude of this station, and near the Red Sea coast, the monsoon has great effect on the wind speed of Al-Baha. As presented in figure 3(a), the power spectral energy, mostly concentrated at $f=0.00269$, which corresponds to a period of about $T=1 / f=372$ days $\approx 1$ yr, implying that wind speed variation in a year is similar to that in another, at least qualitatively. The period of $T \approx 372$ days is not exactly equal to 365 days because of the frequency resolution in the FFT analysis, or it might be connected to a natural phenomenon that wind speed year (i.e., yearly period) is slightly longer than the standard year. The latter is possible as winter and/or summer sometimes come late or early. Further examination on longtime speed history is required to prove it. Peaks at $f=0.00537$ and 0.0083 are also evident (figure $3 \mathrm{a}$ ), associated with half-year and four-month periods, respectively. Interestingly, the power spectrum for Najran (figure 3f) as well as Taif (figure 3h) is similar to that of Al-Baha (figure 3a), owing to their high geographical location. Najran, located southeast of Khamis-Mushait, is also a highland, $\sim 1290 \mathrm{~m}$ above the mean sea level (MSL), having topographical features of $1200-500 \mathrm{~m}$ in the north, $1400-1600 \mathrm{~m}$ in the south, $1500-1600 \mathrm{~m}$ in the east, and 1500 to $2000 \mathrm{~m}$ in the west. It can be considered as a region with gentle topographical features. Taif is a hill station in the west of Saudi Arabia with about $1880 \mathrm{~m}$ AMSL. In the north, the land elevation varies from 800 to $1000 \mathrm{~m}$, while it ranges from 800 to $1200 \mathrm{~m}$ in the south. The eastern region has land elevation varying from 1400 to $1500 \mathrm{~m}$, while in the west, the land elevation varies from 600 to $800 \mathrm{~m}$. All three stations have peaks
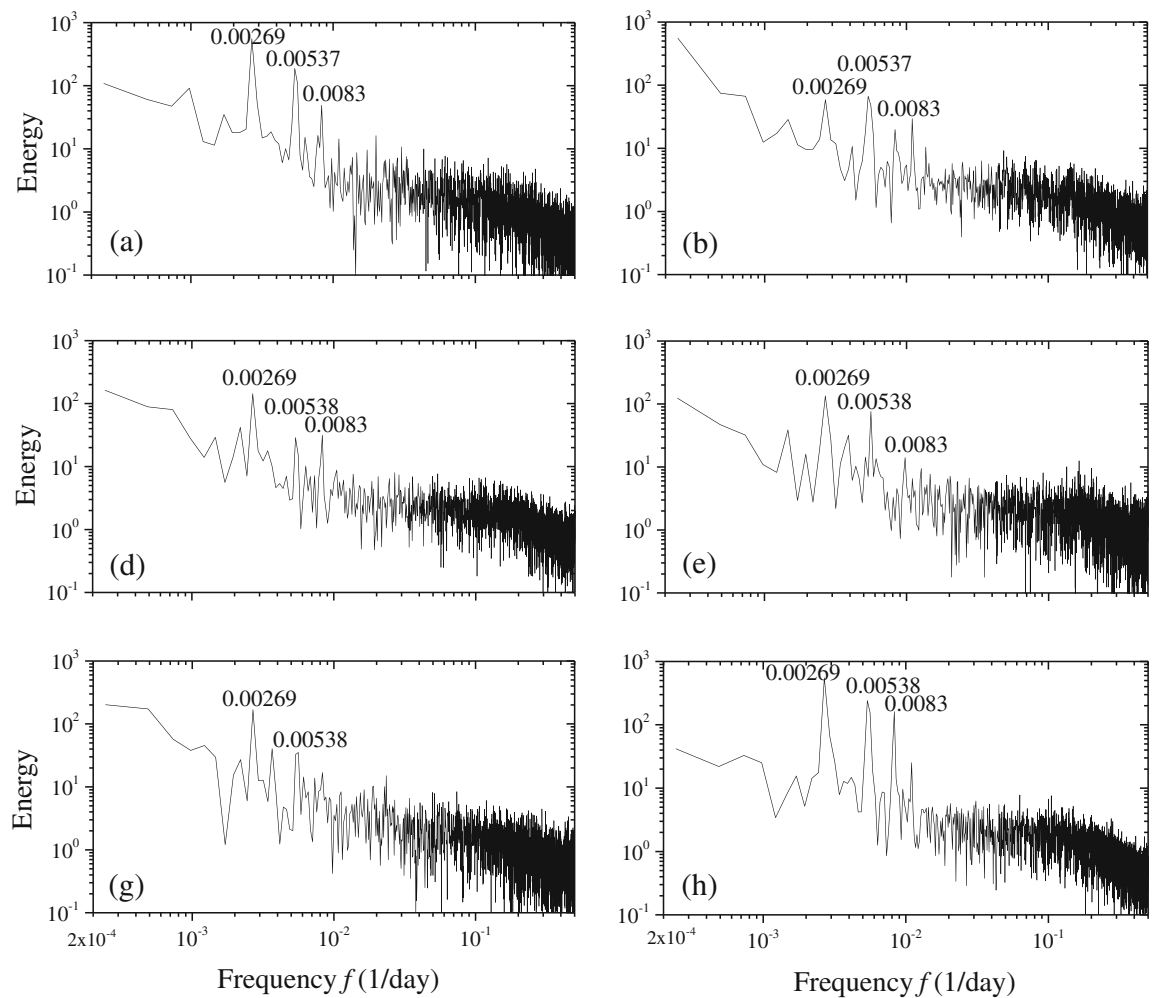
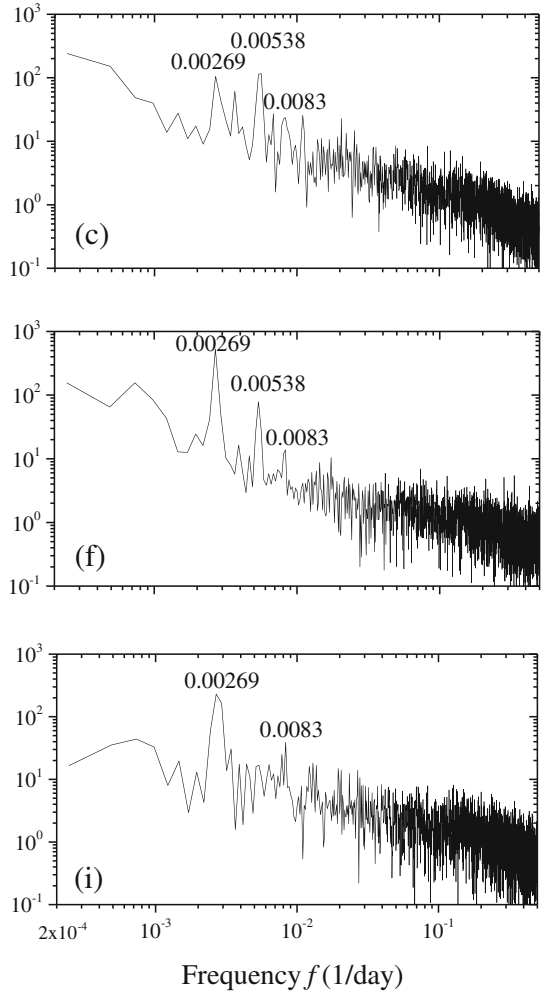

Figure 3. The power spectra of daily averaged wind speed time series data at the nine locations. (a) Al-Baha; (b) Bisha; (c) Khamis-Mushait; (d) Madinah; (e) Mecca; (f) Najran; (g) Sharourah; (h) Taif; and (i) Wadi-Al-Dawasser. 
at $f=0.00269,0.00537$ and 0.0083 , although the peak at $f=0.0083$ is weak for Najran. The peak at $f=0.00269$ for Wadi-Al-Dawasser (figure 3i) is also prominent. This station is located in the southeast region of Saudi Arabia near the RubAlkhali (Empty Quarter) desserts at an elevation of $650 \mathrm{~m}$ above MSL, having almost no structures or mountains around it. It is an inland location. The north and south regions have elevations between 600 and $800 \mathrm{~m}$, while the western region has elevations of about 700-900 m. The effect of monsoon is relatively smaller than the other three locations, because it is kept away from the Red Sea coast. And thus, the peak at $f=0.00269$ being broader (figure 3i) means that the annual repeat characteristic is relatively weaker. This power spectrum feature is consistent with the autocorrelation result, which is given in the following part. However, the power spectra at these four locations have similar identities, with a notable peak at $f=0.00269$ and smaller energy at low frequencies $(f<0.001)$.

Bisha, an inland area located in the east of Al-Baha, has topographical features with elevations varying from 1200 to $1300 \mathrm{~m}$ and can be considered as an area with hillock features. There is a small single-storied airport building in the vicinity of the meteorological station. The peaks at $f=0.00269$ and 0.00537 (figure 3b) are much lower than those of Al-Baha, and the power spectral energy mostly concentrates on a low-frequency range $(f<0.001)$. It might be connected to the fact that the wind on an inland area is interrupted by high-rise buildings and structures, such as bridges or other industrial installations, and the wind speed fluctuation was thus smaller than that for Al-Baha.

Again, the characteristics of power spectra for Khamis-Mushait and Makkah (figure 3c, e) resemble those for Bisha, peaks at $f=0.00269$ and 0.00537 being comparable to each other for the three locations. The observation is different from Al-Baha, Najran, and Taif, where the peak at the latter frequency is smaller compared to that at the former. Khamis-Mushait is a flat inland area with elevations varying from 2000 to $2100 \mathrm{~m}$ in the south of Bisha; there is one small single-storied airport building and some trees around. Makkah, only $277 \mathrm{~m}$ above the mean sea level, is situated southwest of Taif, and approximately $80 \mathrm{~km}$ inland from the Red Sea in the west, surrounded by a range of high mountains with elevations varying from 1600 to $1700 \mathrm{~m}$ from north, south, and east directions. The high-rise buildings and mountains interrupted the wind, resulting in the smaller peak at $f=0.00269$, and thus the power spectrum energy concentrated on the lower frequency range.

Topographically, Madinah is located at 650 above MSL in the west of the country, surrounded by mountains of $600-800 \mathrm{~m}$ in the north, $800-850 \mathrm{~m}$ in the south, 800-900 $\mathrm{m}$ in the east, and around 800 $\mathrm{m}$ in the west. Hence, it can be considered as an inland valley surrounded by mountains. The power spectral energy on the lower frequency range $(f<$ 0.001 ) is again discernible (figure $3 \mathrm{~d}$ ), and the peak at $f=0.00269$ is not as prominent as that for AlBaha, because Madinah as an inland valley receives a low fluctuation in wind interrupted by the buildings and mountains. Furthermore, different from that for Bisha and Khamis-Mushait, the peak at $f=0.00537$ for Madinah is not so remarkable.

The Sharourah meteorological station is in the mainland and located east of Najran around $722 \mathrm{~m}$ above the mean sea level, and thus receive negligible influence from monsoon. Therefore, the power spectrum for Sharourah resembles that for Madinah.

The detailed discussion above revealed that Al-Baha, Najran, Taif and Wadi-Al-Dawasser having a sharp peak at $f=0.00269$, retain a more regular annual repetition of wind speed than Bisha, Khamis-Mushait, Madinah, Makkah, and Sharourah. Surrounding structures and mountains play a dominant role in determining the wind speed and its fluctuations. Wavelet analysis results in the following section will provide more inherent details.

\subsection{Autocorrelation function}

Autocorrelation analysis results can provide more information on the repetition of the wind speed at the prominent frequencies. Autocorrelation involves matching the signal with a copy of that signal, which is extended or delayed in the time axis, identifying the presence of a periodic signal removing noise. Autocorrelation coefficient $R_{u u}$ of wind speed $u$ is indeed a cross-correlation between $u$ and $\bar{u}$, defined as:

$$
R_{u u}(\tau)=\frac{\overline{\{u(t)-\bar{u}\}\{u(t+\tau)-\bar{u}\}}}{\overline{(u-\bar{u})^{2}}},
$$

where $\tau$ is the time delay (over-bar stands for timeaveraged).

Figure 4 illustrates $R_{u u}$ function for the nine stations. The periodic characteristics of the wind speed are reflected in the $R_{u u}$ functions. The first prominent peak in $R_{u u}$ appears at $\tau \approx 370$ days corresponding to annual variation or peak at $f=$ 0.00269 in the power spectrum shown in figure 3 . The peak is, however, sharper for Al-Baha, Najran, Taif and Wadi-Al-Dawasser (figure 4a, f, h, i), where the peak at $f=0.00269$ in power spectra (figure 3 ) was prominent. For these locations, $R_{u u}$ continues its modulation with decaying amplitude with a period $T \approx 370$ days. This is the longest period observed in the power spectra. Now we can pay 

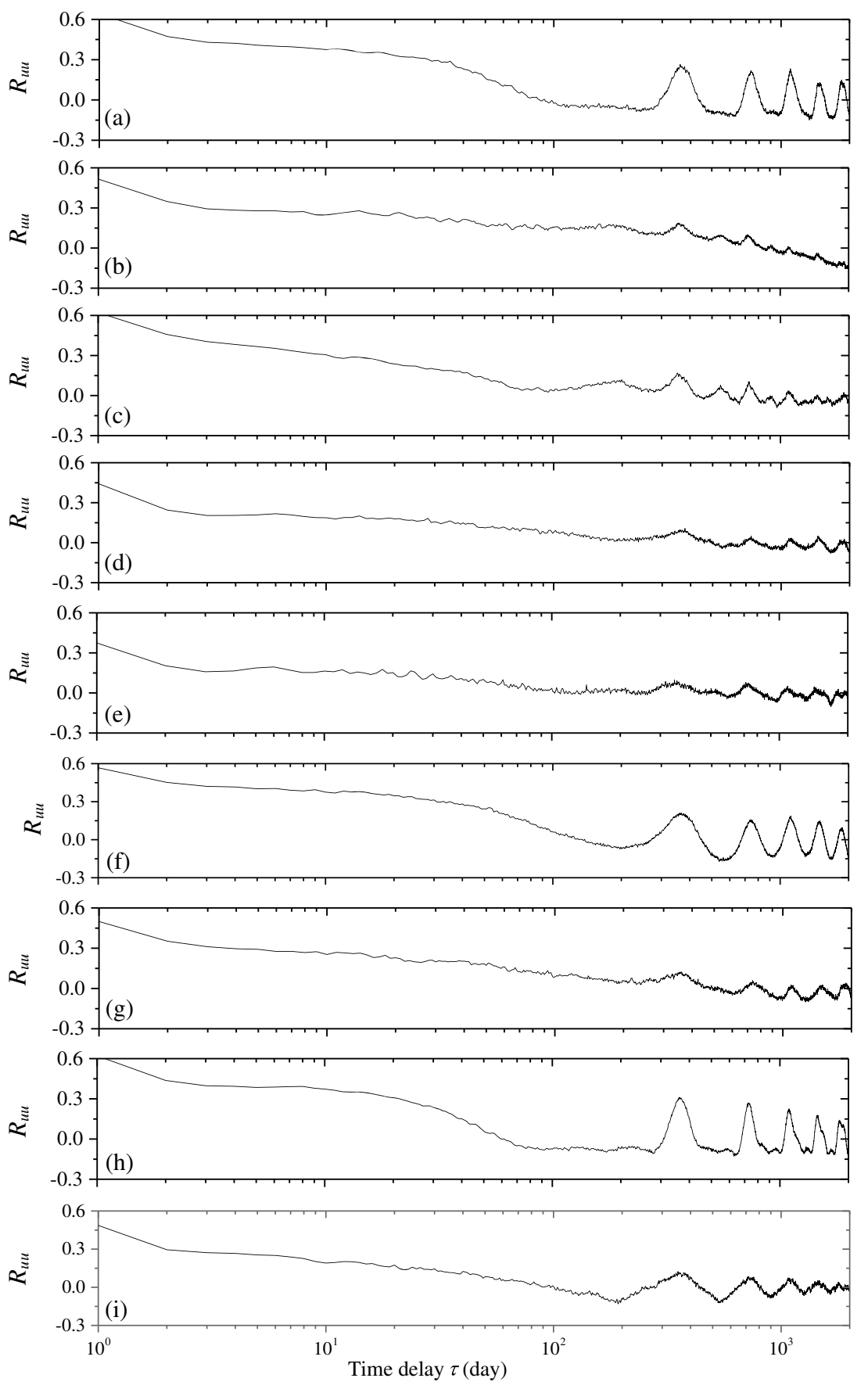

Figure 4. The autocorrelation coefficient $R_{u u}$ of daily averaged wind speed time series data at the nine locations. (a) Al-Baha; (b) Bisha; (c) Khamis-Mushait; (d) Madinah; (e) Mecca; (f) Najran; (g) Sharourah; (h) Taif; and (i) Wadi-Al-Dawasser.

attention to the decay of $R_{u u}$ in the first half period (i.e., $\tau<T / 2=185$ days).

Considering $T \approx 370$ days, the first valley appears at $\tau=T / 2 \approx 185$ days. The valley at $\tau=$ $T / 2$ for Najran and Wadi-Al-Dawasser (figure 4f, i) is clear, and $R_{u u}$ modulation beyond the first peak for these two locations is almost symmetric about $R_{u u}=0$. The first valley as well as $R_{u u}$ modulation is interrupted for other locations, for example, see figure $(4 \mathrm{a}, \mathrm{h})$, where $R_{u u}$ at $\tau=(n+1) T / 2$ (i.e., at the valleys, where $n=0,1,2, \ldots)$ is restricted.
The prevailing half-year period is the cause of the $R_{u u}$ interruption at $\tau=(n+1) T / 2$. It was noted that the peak at $f=0.00537$ in the power spectra was weak or absent for Najran and Wadi-AlDawasser (figure $3 \mathrm{f}, \mathrm{i}$ ). Interruption for these two locations is, therefore, insignificant. For Bisha and Khamis-Mushait, where the peaks at $f=0.00269$ and 0.00537 have a similar intensity (figure 3b, c), $R_{u u}$ reached a small peak at $\tau \approx 185$ days due to the predominance of a half-year period corresponding to $f=0.00537$. Based on the above results, 
the nine locations can be divided into three groups, namely, (A) Al-Baha, Najran, Taif, and Wadi-AlDawasser, where the annual modulation of wind speed was strong (figures $3 \mathrm{a}, \mathrm{f}, \mathrm{h}, \mathrm{i}$ and $4 \mathrm{a}, \mathrm{f}, \mathrm{h}, \mathrm{i}$ ), (B) Bisha, Khamis-Mushait, and Mecca, where the annual and half-year modulations of wind speed was comparable to each other (figures $3 \mathrm{~b}$, c, e and 4b, c, e), and (C) Madinah and Sharourah, where the annual modulation was moderately prominent (figures $3 \mathrm{~d}, \mathrm{~g}$ and $4 \mathrm{~d}, \mathrm{~g}$ ). The first group can be further subdivided into two: $\left(\mathrm{A}_{1}\right)$ Al-Baha and Taif, where half-year modulation was also considerable (figures $3 \mathrm{a}, \mathrm{h}$ and $4 \mathrm{a}, \mathrm{h}$ ), and $\left(\mathrm{A}_{2}\right)$ Najran and Wadi-Al-Dawasser, where the half-year modulation was insignificant (figures 3f, i and 4f, i).

\subsection{Wavelet decomposition}

As the data used in this study were daily mean values, hence the signal captured the information for a period longer than 2 days following the Nyquist frequency criterion. A discrete wavelet analysis of the daily mean values of wind speed time series data was conducted for the nine locations using db8 (Daubechies wavelets). Here, eight decomposition levels are selected to split the raw signal into components with different periods: longterm (more than one year), a period of one year, half year, a quarter year, bi-month, one month, bi-week, one week and half week, respectively, which are widely used as the characteristic time length to describe the wind speed fluctuation.

In the previous section, the locations were divided into groups A (A1, A2), B and C. In this analysis also similarities were based in similar group of stations, as mentioned before. We will, therefore, discuss wavelet analysis results for a representative location from each group. The wavelet decomposition results of wind speed data for Al-Baha, Wadi-Al-Dawasser, Khamis-Mushait, Shrourah are shown in figures 5, 6, 7 and 8, respectively, representing groups A1, A2, B and C. In these figures, the $\mathrm{x}$-axis presents time (day) of the entire data period. Each figure is composed of 10 signals.

The first part ' $s$ ' represents the raw signal and the second part ' $a_{8}$ ' corresponds to the approximation of the raw signal for Daubechies wavelets $(\mathrm{db})$ at level 8 corresponding to a period longer than 512 days. The last eight parts, i.e., $d 1, d 2, d 3, d 4, d 5$, $d 6, d^{r} 7$ and $d 8$ in these figures represent the decomposed details of the raw signal at eight different levels corresponding to the period ranges $2-4,4-8$, 8-16, 16-32, 32-64, 64-128, 128-256 and 256-512 days, respectively.

Figure 5 shows the decomposition of wind speed time series data for Al-Baha (group $\mathrm{A}_{1}$ ) and power spectra of the decomposed signals. The raw signal ' $s$ ' in figure 5(a) (Al-Baha) displays a sharp spike at
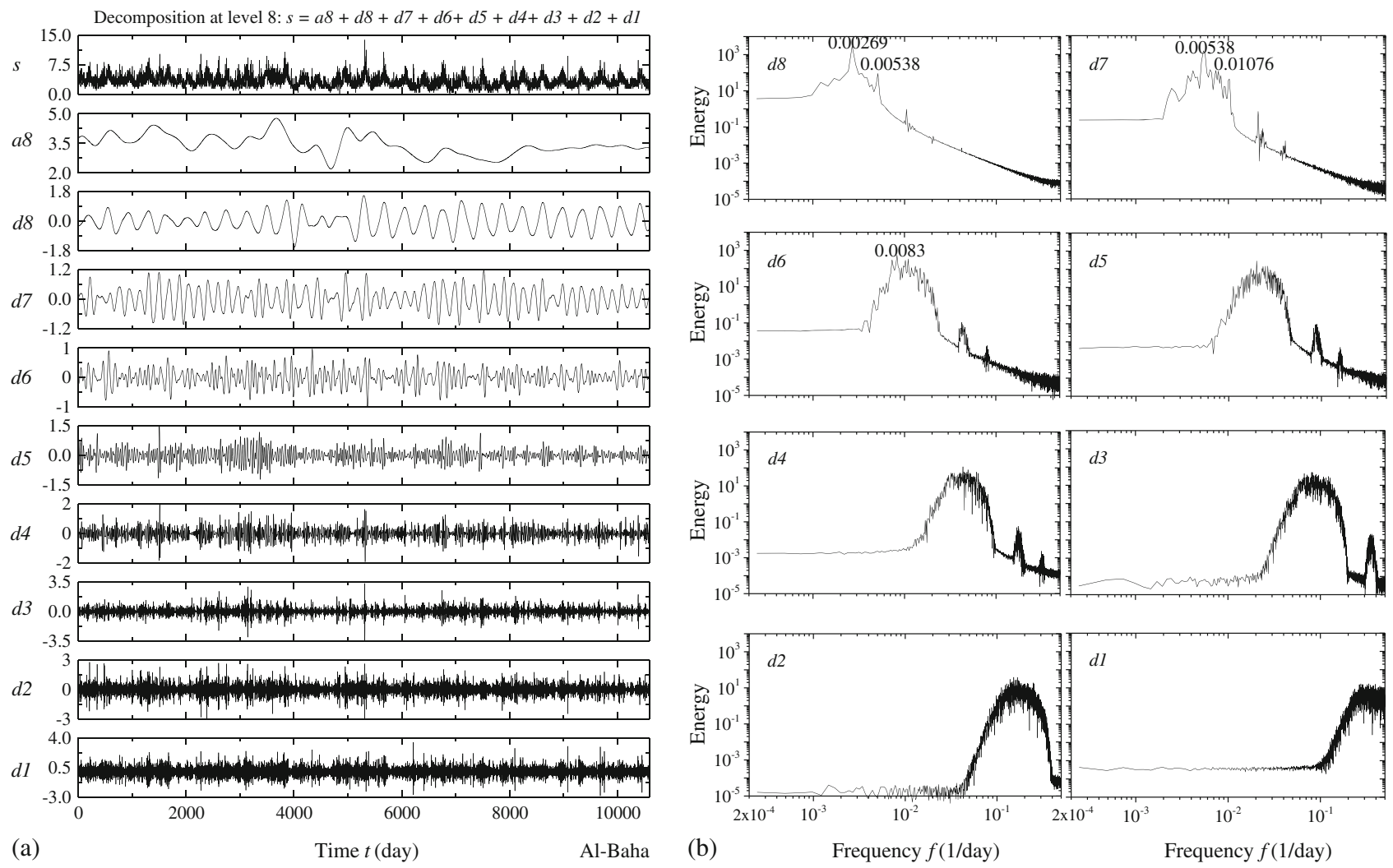

Figure 5. (a) Decomposition of wind speed time series data and (b) the power spectra of decomposed signals. Al-Baha. 

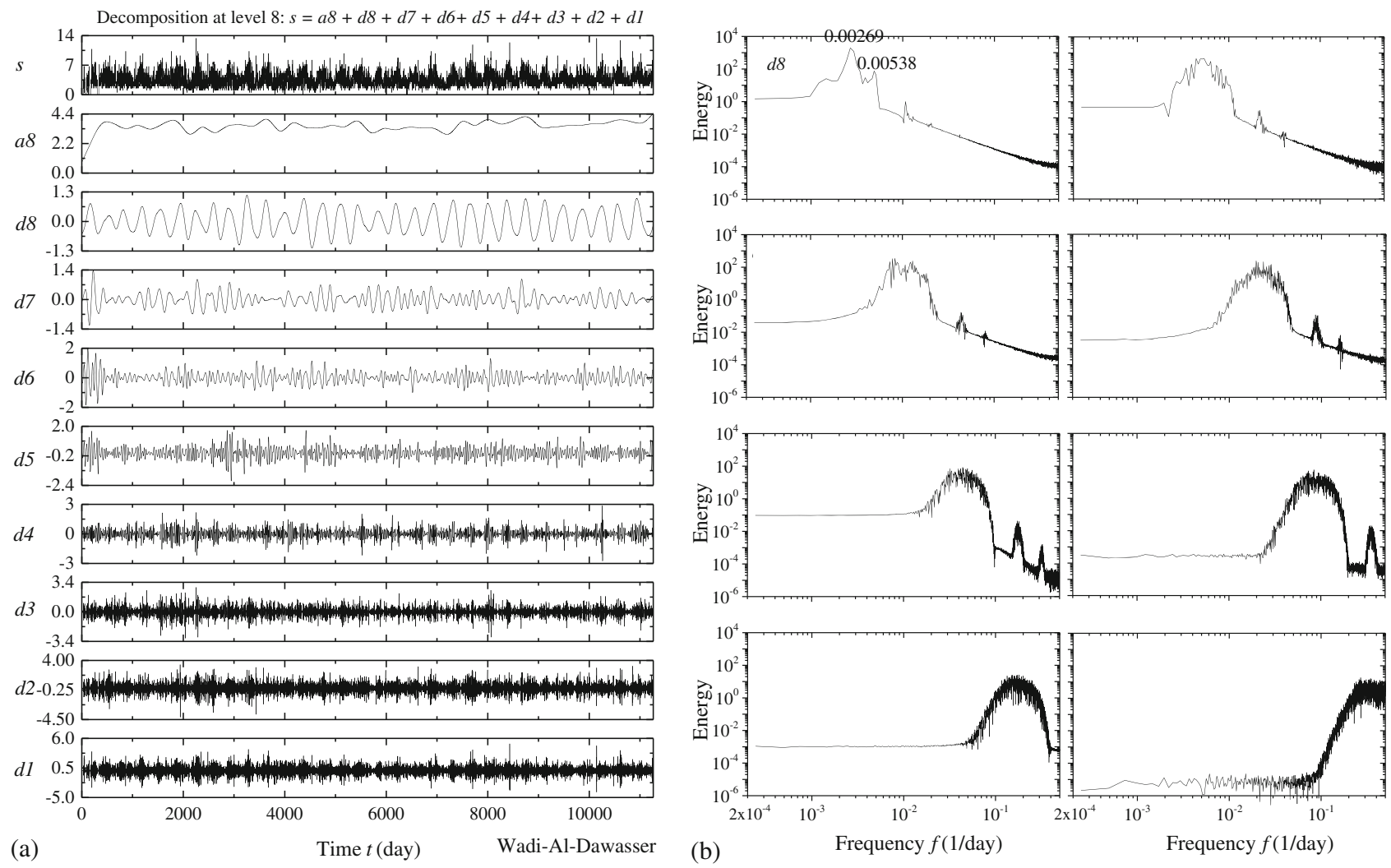

Figure 6. (a) Decomposition of wind speed time series data and (b) the power spectra of decomposed signals. Wadi-AlDawasser.
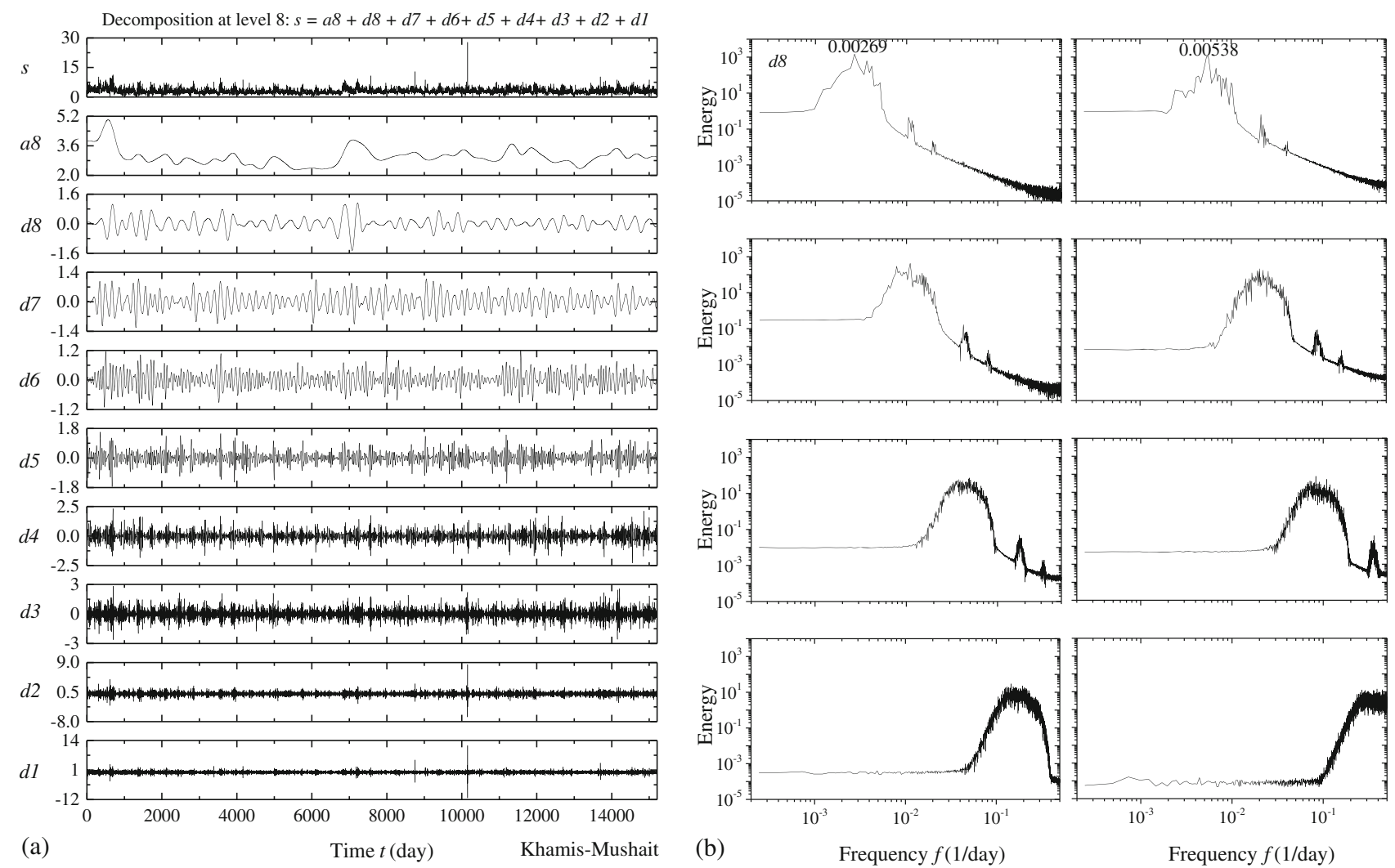

Figure 7. (a) Decomposition of wind speed time series data and (b) the power spectra of decomposed signals. KhamisMushait. 

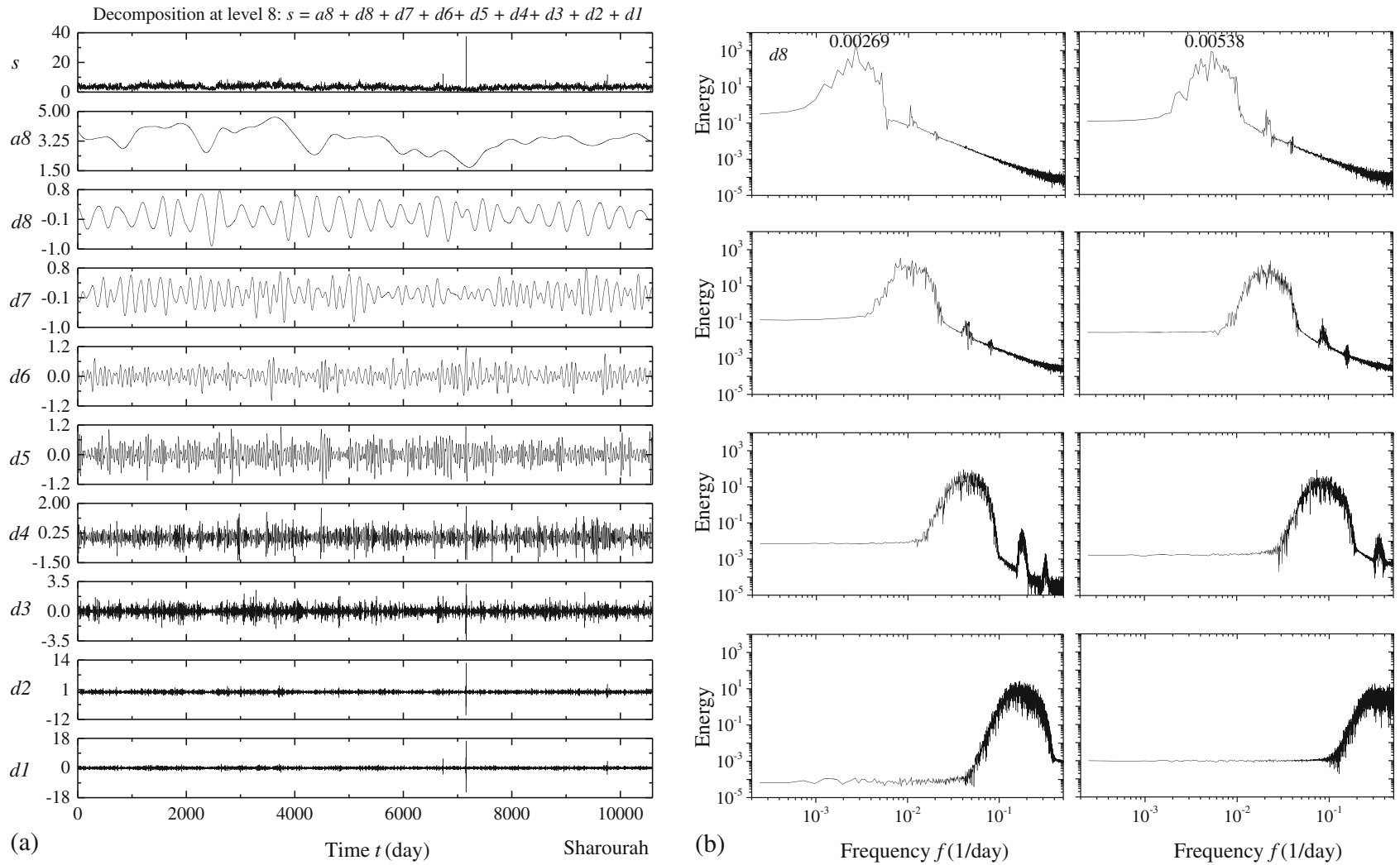

Figure 8. (a) Decomposition of wind speed time series data and (b) the power spectra of decomposed signals. Sharourah.

Table 4. Intrinsic features of wind speed at different locations. June-August is the wind peak season.

$\frac{a 8 \text { Long-term }}{\text { Mean }}$
wind
speed Fluctuation Yearly Half-yearly Quarterly Bi-monthly Monthly Bi-weekly Weekly Half-weekly

\begin{tabular}{lcccccccccc} 
Station name & $(\mathrm{m} / \mathrm{s})$ & $(\mathrm{m} / \mathrm{s})$ & $d 8$ & $d 7$ & $d 6$ & $d 5$ & $d 4$ & $d 3$ & $d 2$ & $d 1$ \\
\hline Al-Baha & 3.41 & \pm 0.80 & \pm 0.91 & \pm 0.59 & \pm 0.49 & \pm 0.50 & \pm 0.50 & \pm 0.67 & \pm 0.82 & \pm 0.89 \\
Bisha & 2.49 & \pm 0.87 & \pm 0.35 & \pm 0.50 & \pm 0.30 & \pm 0.36 & \pm 0.53 & \pm 0.66 & \pm 0.92 & \pm 0.90 \\
Khamis-Mushait & 3.00 & \pm 0.90 & \pm 0.53 & \pm 0.69 & \pm 0.41 & \pm 0.48 & \pm 0.57 & \pm 0.81 & \pm 0.93 & \pm 0.90 \\
Madinah & 3.18 & \pm 0.77 & \pm 0.42 & \pm 0.34 & \pm 0.29 & \pm 0.34 & \pm 0.47 & \pm 0.73 & \pm 0.92 & \pm 1.00 \\
Mecca & 1.45 & \pm 0.49 & \pm 0.25 & \pm 0.25 & \pm 0.17 & \pm 0.18 & \pm 0.27 & \pm 0.36 & \pm 0.51 & \pm 0.61 \\
Najran & 2.24 & \pm 0.77 & \pm 0.64 & \pm 0.35 & \pm 0.26 & \pm 0.30 & \pm 0.36 & \pm 0.51 & \pm 0.66 & \pm 0.77 \\
Sharourah & 3.32 & \pm 0.89 & \pm 0.47 & \pm 0.41 & \pm 0.41 & \pm 0.37 & \pm 0.46 & \pm 0.75 & \pm 0.94 & \pm 0.99 \\
Taif & 3.72 & \pm 0.48 & \pm 0.97 & \pm 0.90 & \pm 0.49 & \pm 0.47 & \pm 0.59 & \pm 0.72 & \pm 1.13 & \pm 1.13 \\
Wadi-Al-Dawasser & 3.50 & \pm 0.48 & \pm 0.80 & \pm 0.48 & \pm 0.59 & \pm 0.59 & \pm 0.70 & \pm 0.80 & \pm 1.20 & \pm 1.23 \\
\hline
\end{tabular}

$D=5309$ (corresponding to the year 1999) and a nearly regular variation of wind speed. Similarly, other spikes of wind speed are observed at $D=$ 1511, 2273, 3831, 5662, and 9077 corresponding to years 1989, 1991, 1995, 2000, and 2009, respectively. As signal $a_{8}$ corresponds to the approximation of the raw signal corresponding to a period of longer than 512 days, long-term fluctuation and mean can be seen here. The mean speed over the whole duration in signal $a_{8}$ is about $3.41 \mathrm{~m} / \mathrm{s}$, which is very close to that in table 3 ; the fluctuation in signal $a_{8}$ is about $\pm 0.80 \mathrm{~m} / \mathrm{s}$. A regular variation is evident in signal $d 8$ with a periodicity of approximately 372 days (one year), forming a peak between June and August of each year and a minimum in December-January. Figure 5(b) illustrates the power spectral density functions of the decomposed signals $d 8-d 1$. The power spectrum (figure $5 \mathrm{~b}$ ) of the signal $d 8$ displays a sharp and prominent peak at $f=0.00269$ corresponding to one year period, which suggests that annual variation is regular. A superharmonic $(f=0.00538)$ 
of $f=0.00269$ emerges, albeit with a weak peak. The presence of a superharmonic peak is very common when the signal has a strong periodicity. The fluctuation of the speed (signal $d 8$ ) is relatively low, $\pm 0.56 \mathrm{~m} / \mathrm{s}$, for $D<3340(<$ year 1994$)$ and high $\pm 1.27 \mathrm{~m} / \mathrm{s}$, for $3340<D<5470$ (between years 1994 and 2000$)$ and small, $\pm 0.92 \mathrm{~m} / \mathrm{s}$, for $D>5470$ (> year 200). On an average, the annual fluctuation that contributes to wind speed variation is $\pm 0.91 \mathrm{~m} / \mathrm{s}$, obtained as $\pm \sqrt{ } 2 \times \mathrm{rms}$, where rms stands for the root-mean-square of the signal. Signals $d 7$ and $d 6$ display oscillation with a period of about a half and a quarter year, respectively. The oscillation is, however, large for signal $d 7( \pm 0.59 \mathrm{~m} / \mathrm{s})$ compared to that for signal $d 6$ $( \pm 0.49 \mathrm{~m} / \mathrm{s})$. Again, the variation in signal $d 7$ is regular with a strong peak appearing at $f=$ 0.00538 (figure 5b). However, the power spectrum of signal $d 6$ exhibits a blunt peak at $f \approx 0.0083$ (4-month period). All these information is internally consistent with that from figure 3(a). The $d 5$ and $d 4$ signals have large amplitude modulations in the ranges of peaks in $d 8$ signal. The fluctuation $( \pm 0.50 \mathrm{~m} / \mathrm{s})$ in signal $d 5$ is similar to that $(\approx \pm 0.50 \mathrm{~m} / \mathrm{s})$ in signal $d 4$, comparable to that in signal $d 6$. The observation insinuates that the variation in wind speed does not differ much from one-month to four-month scales for this location. Evidently, the spike at $t=1511$ occurs in the signals $d 5$ and $d 4$, corresponding to a wind speed of $10.3 \mathrm{~m} / \mathrm{s}$ in the year 1989 (see signal ' $s$ '). It can be explained that there was a strong wind in that period (one or two months) in the year. Similarly, signals $d 4, d 3$ and $d 2$ display the spike at $D$ $=5309$ (corresponding to the spike of a wind speed of $13.9 \mathrm{~m} / \mathrm{s}$ at the raw signal ' $s$ ' in the year 1999). The spike in signal $d 3$ is, however, larger than that in signals $d 4$ and $d 2$, and it can be explained with a view on signal $d 3$ that there was a persistent wind gust or storm in a period of $8 \sim 16$ days. Again, several wind gusts are observed in signal $d 1$, such as $D=6215$ (year 2002), 8095 (year 2007), 9077 (year 2009), and 9680 (year 2011) for a shorter period of $2 \sim 4$ days. The fluctuation in wind speed gets stronger in signals $d 2$ and $d 1$ than signal $d 3$ and $d 4$. Overall, the wind speed fluctuation is stronger for long-term $(a 8)$ and a period of one year $(d 8)$, one week $(d 2)$ and half week $(d 1)$, but relatively weaker for a period of half year $(d y)$ and bi-week (d3), and further weaker for a period of a quarter year $(d 6)$, bi-month $(d 5)$, one month $\left(d_{4}\right)$.

The decomposition of wind speed time series data and the power spectra of the detailed signals for Wadi-Al-Dawasser (group A2) are shown in figure 6 . Here the long-term variation $(a 8)$ in wind speed occurs from 3.00 to $3.97 \mathrm{~m} / \mathrm{s}$ with the mean and fluctuation over the entire duration being $3.50 \mathrm{~m} / \mathrm{s}$ and $\pm 0.48 \mathrm{~m} / \mathrm{s}$, respectively.
The annual variation of wind speed (signal $d 8$ ) is more regular for Wadi-Al-Dawasser than Al-Baha. The regularity is also reflected in the power spectrum results (figure 6b) with an obvious peak at $f=0.00269$. The annual variation in amplitudes at Wadi-Al-Dawasser is about $\pm 0.8 \mathrm{~m} / \mathrm{s}$, slightly smaller than that at Al-Baha $( \pm 0.91 \mathrm{~m} / \mathrm{s})$. Different from Al-Baha, the half-yearly variation of wind speed ( $d 7$ signal) is very irregular, which is also reflected from power spectrum results (figure $6 \mathrm{~b}$ ), internally consistent with the absence of the peak at half-year period in the power spectrum in figure 3(i). The wind speed fluctuations of other detailed signals $d 6, d 5, d 4, d 3, d 2$ and $d 1$ are $\pm 0.59, \pm 0.59, \pm 0.70, \pm 0.80, \pm 1.20$ and $\pm 1.23 \mathrm{~m} / \mathrm{s}$, respectively, larger than those of Al-Baha.

Shown in figure 7 are the decomposed wind speed time series data and the power spectra of the decomposed signals for Khamis-Mushait (group B). The raw signal ' $s$ ' of wind speed shows two sharp peaks at $D=8756$ (year 1995) and $D=10156$ (year 1999) associated with wind speeds of 12.86 and $27.78 \mathrm{~m} / \mathrm{s}$, respectively. The latter higher wind speed is very important to be considered in the design of the wind turbines. The long-term mean wind speed and the fluctuation are about 3.00 and $\pm 0.90 \mathrm{~m} / \mathrm{s}$, respectively ( $a 8$ signal). The annual fluctuation is relatively small here, about \pm 0.53 $\mathrm{m} / \mathrm{s}$ (signal $d 8$ ), more irregular compared to that for Al-Baha and Wadi-Al-Dawasser. The peak at $f=0.00269$ (figure 7b) is therefore not as sharp and prominent as observed for Al-Baha and WadiAl-Dawasser. On the contrary, the half-yearly variation (signal $d^{r}$ ) in amplitude is relatively larger (about $\pm 0.69 \mathrm{~m} / \mathrm{s}$ ) and regular.

The power spectrum of $d^{r} 7$ signal (figure $7 \mathrm{~b}$ ) further confirms the above observation, where the peak at $f=0.00538$ is distinct. Evidently, the above discussion on the wavelet result agrees well with the FFT results (figure 3c). In figure 3(c), the peak at $f=0.00538$ became more prominent compared with that at $f=0.00269$, meaning that the wind with half-year period would play the same role as that with one-year period. The quarterly $(d 6)$, bimonthly (d5), monthly $(d / 4)$ and half-weekly $(d 1)$ wind speed fluctuations are close to their counterparts in Al-Baha, equaling to $\pm 0.41, \pm 0.48$, \pm 0.57 and $\pm 0.90 \mathrm{~m} / \mathrm{s}$, respectively. The bi-weekly (d3) and weekly (d2) fluctuations are about \pm 0.81 and $\pm 0.93 \mathrm{~m} / \mathrm{s}$, respectively, larger than those for Al-Baha.

The decomposed wind speed time series data and their power spectra for Sharourah (group C) are presented in figure 8 . The raw signal ' $s$ ' of wind speed shows two sharp peaks at $D=6731$ (year 2003) and $D=7156$ (year 2004) associated with wind speeds of 12.35 and $37.55 \mathrm{~m} / \mathrm{s}$, respectively. The long-term mean wind speed and fluctuation 
are about 3.32 and $\pm 0.89 \mathrm{~m} / \mathrm{s}$, respectively (signal $a 8$ ). The annual wind speed fluctuation (signal $d 8$ ) is relatively small here, i.e., about $\pm 0.47 \mathrm{~m} / \mathrm{s}$, but larger than the half-yearly fluctuation of about $\pm 0.41 \mathrm{~m} / \mathrm{s}$ (signal $d^{7}$ ) and different from that for Khamis-Mushait (group B). Further, different from those for Al-Baha and Wadi-Al-Dawasser (group A), both annual and half-yearly fluctuations are much smaller than the long-term fluctuation (signal $a 8)$, which is consistent with figure $3(\mathrm{~g})$, where the power spectral energy mostly concentrated on low-frequency range $(f<0.001)$. The above discussion can be confirmed by the power spectra of detailed signals $d 8$ and $d 7$ (figure $8 \mathrm{~b}$ ), where the peak at $f=0.00269$ is more clear and prominent than that at $f=0.00538$. The wind speed fluctuations for a period of a quarter year $(d 6)$, bi-month $(d 5)$, one month and bi-week are about $\pm 0.41, \pm 0.37, \pm 0.46$ and $\pm 0.75 \mathrm{~m} / \mathrm{s}$, respectively, while those for a period of one week and half week

(a)
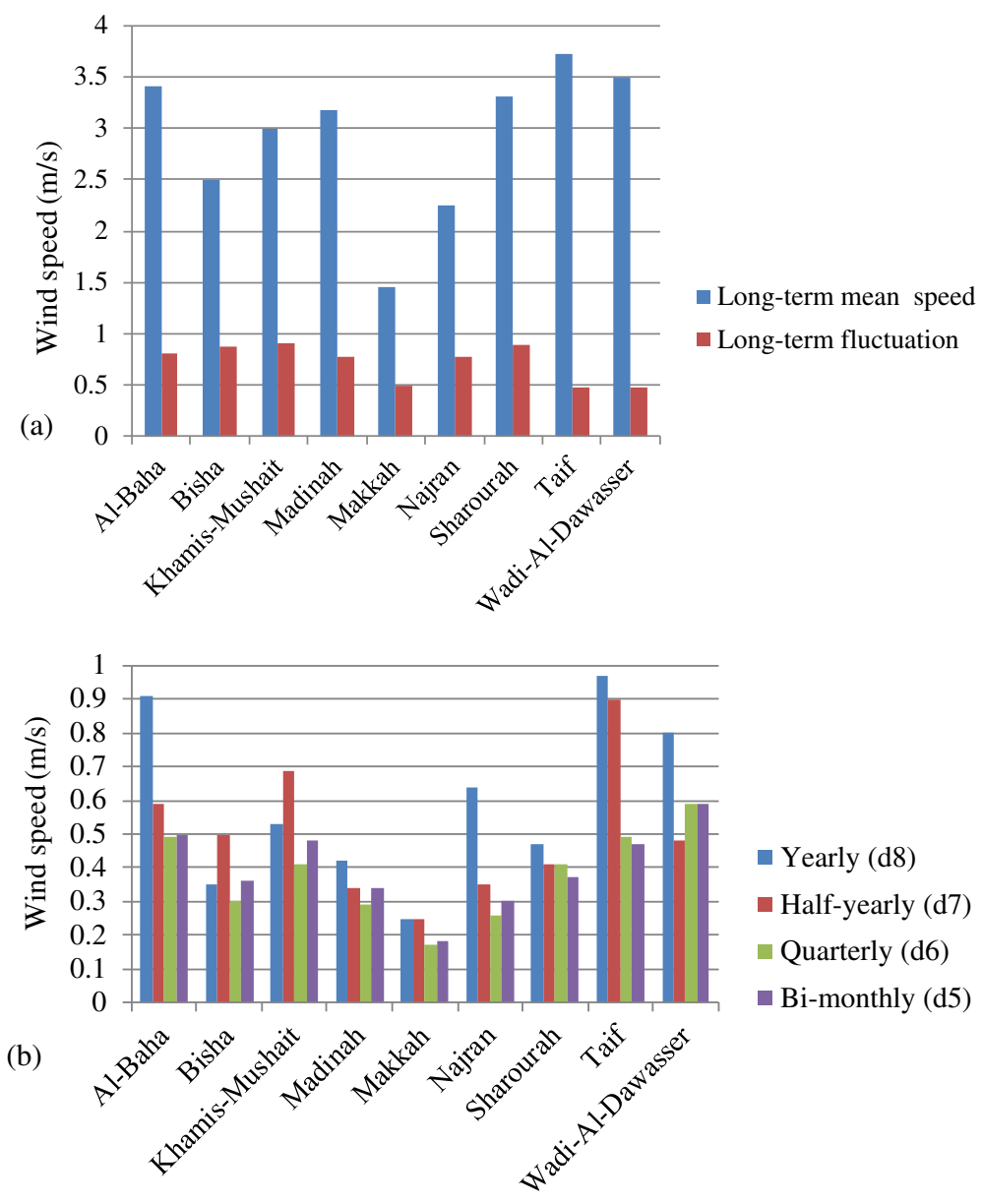

- Yearly (d8)

- Half-yearly (d7)

Quarterly (d6)

- Bi-monthly (d5)

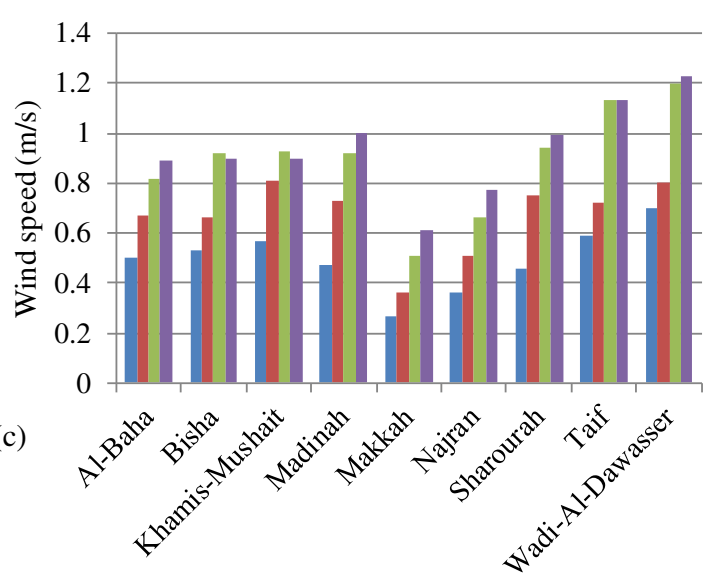

- Monthly (d4)

- Bi-weekly (d3)

Weekly (d2)

- Half-weekly (d1)

(c)

Figure 9. (a) Long-term mean wind speed and fluctuation for all the stations and $(\mathbf{b}-\mathbf{c})$ wind speed fluctuations for different decomposed details. 
are much higher, equaling to \pm 0.94 and $\pm 0.99 \mathrm{~m} / \mathrm{s}$. The signals $d 4, d 3, d 2$ and $d 1$ display a spike at $D=7156$ (corresponding to the spike of a wind speed of $37.55 \mathrm{~m} / \mathrm{s}$ at the raw signal ' $s$ ' in the year 2004). The spike in signals $d 2$ and $d 1$ is, however, much greater than that in signals $d 4$ and $d 3$. It can be explained that there was a persistent wind gust or storm in this one week period. Similarly, the spike in signal $d 1$ at $D=6731$ (year 2003) corresponds to a wind gust in a period of $2 \sim 4$ days.

Table 4 summarizes the important intrinsic features of wind speed analysis results using wavelet method (figures 5-8 and figures A1-A5 in the appendix). The long-term $(29,31,36$ and 42 years) mean speed (second column) and long-term fluctuations (third column) were extracted from signals a8. The yearly, half-yearly, quarterly, bimonthly, monthly, bi-weekly, weekly and half-weekly fluctuations in speed obtained from signals $d 8, d 7$, $d 6, d 5, d 4, d 3, d 2$ and $d 1$ are summarized in the column numbers $4-11$, respectively. The long-term mean wind speed and fluctuation for all the stations are shown in figure $9(\mathrm{a})$, while the wind speed fluctuations for the different decomposed detail signals are presented in figures 9 (b and c), for the sake of a better perceptibility of the comparison between the different locations. The longterm mean wind speed varies from a minimum of $1.45 \mathrm{~m} / \mathrm{s}$ at Mecca to a maximum of 3.72 $\mathrm{m} / \mathrm{s}$ at Taif (table 4 and figure 9a). At Al-Baha, Khamis-Mushait, Madinah, Sharourah, Taif and Wadi-Al-Dawasser, the long-term mean wind speed is greater than $3.0 \mathrm{~m} / \mathrm{s}$. The long-term fluctuation is larger at Bisha, Khamis-Mushait and Sharourah $(\approx \pm 0.87 \sim \pm 0.90 \mathrm{~m} / \mathrm{s})$, and relatively smaller at Al-Baha, Madinah and Najran $(\approx \pm 0.77 \sim \pm 0.80$ $\mathrm{m} / \mathrm{s}$ ), and further less at Mecca, Taif and Wadi-AlDawasser $(\approx \pm 0.48 \mathrm{~m} / \mathrm{s})$. The information on longterm mean and fluctuation wind speed is crucial to decide the locations of wind farms.

The annual variation is the largest $( \pm 0.97 \mathrm{~m} / \mathrm{s})$ at Taif and the smallest $( \pm 0.25 \mathrm{~m} / \mathrm{s})$ at Mecca as shown in figure $9(\mathrm{~b})$. Similarly, the half-yearly wind speed fluctuation varies between \pm 0.25 and \pm 0.90 $\mathrm{m} / \mathrm{s}$, as can be seen from the data provided in the 5 th column of table 4 and figure 9(b). The quarterly and bi-monthly fluctuations in wind speed are given in the 6 th and 7 th columns of table 4 . The minimum $(\approx \pm 0.175 \mathrm{~m} / \mathrm{s})$ and maximum $(\approx$ $\pm 0.59 \mathrm{~m} / \mathrm{s})$ quarterly $(d 6)$ and bi-monthly (d5) fluctuations are observed at Mecca and Wadi-AlDawasser (see table 4 and figure $9 \mathrm{~b}$ ) respectively. The monthly values of wind speed fluctuations vary between \pm 0.27 and $\pm 0.7 \mathrm{~m} / \mathrm{s}$ corresponding to Mecca and Wadi-Al-Dawasser (table 4 and figure 9c). The bi-weekly (d3), weekly (d2), and half-weekly $(d 1)$ wind speed fluctuations are listed in the 9th, 10th and 11th columns of table 4 and also compared in figure 9(c) for better visualization. Interestingly, the yearly fluctuation is larger than half-yearly fluctuation except for Bisha, Khamis-Mushait and Mecca, which all are in group B. Quarterly and bi-monthly fluctuations are comparable to each other. On the other hand, weakly and half-weakly fluctuations being similar to each other are higher than monthly and bimonthly fluctuations. The information in table 4 will be very useful for short- and long-term wind forecasts. For instance, it can be used to distinguish idle and working periods of a wind turbine.

\section{Conclusions}

Fast Fourier transform (FFT), autocorrelation, and wavelet analyses were performed on daily averaged wind speed time series data at nine distinct geographical locations, namely, Al-Baha, Bisha, Khamis-Mushait, Madinah, Mecca, Najran, Sharourah, Taif, and Wadi-Al-Dawasser in Saudi Arabia over the period 1972-2013. The analyses extracted the intrinsic features of wind speed, including the long-term mean wind speed and fluctuations at different time scales (periods). The information on speed fluctuations at different periods is very useful for meteorological purposes including wind power resource assessment in particular and weather forecasting in general.

Based on the FFT and autocorrelation analysis results, the nine locations were divided into three groups, namely, (A) Al-Baha, Najran, Taif, and Wadi-Al-Dawasser, where the annual modulation of wind speed was strong, (B) Bisha, KhamisMushait, and Mecca, where the annual and half-year modulations of wind speed were comparable to each other, and (C) Madinah and Sharourah, where the annual modulation was moderately prominent. Also, the first group was further subdivided into two sub-groups: $\left(\mathrm{A}_{1}\right)$ Al-Baha and Taif, and $\left(\mathrm{A}_{2}\right)$ Najran and Wadi-Al-Dawasser, depending on the fact that the half-year modulation was significant or not. The long-term mean wind speed values were $3.41,2.49,3.00,3.18,1.45,2.24,3.32,3.72$ and $3.50 \mathrm{~m} / \mathrm{s}$ at Al-Baha, Bisha, Khamis-Mushait, Madinah, Mecca, Najran, Sharourah, Taif, and Wadi-Al-Dawasser, respectively. However, the longterm fluctuations varied between a minimum of $\pm 0.48 \mathrm{~m} / \mathrm{s}$ at Taif and Wadi-Al-Dawasser and a maximum of $\pm 0.90 \mathrm{~m} / \mathrm{s}$ at Khamis-Mushait. Annual fluctuation is generally larger than halfyearly fluctuation except for locations in group B with quarterly and bi-monthly fluctuations being comparable to each other. Half-weekly fluctuation does not differ much from weekly fluctuation, and both fluctuations become greater than monthly and bi-monthly fluctuations. Furthermore, among long-term, annual, half-yearly, quarterly, monthly, bi-weekly, weekly and half-weekly 
fluctuations, the annual fluctuation is highly sensitive to geographical location, varying from \pm 0.25 to $\pm 0.97 \mathrm{~m} / \mathrm{s}$ (table 4 , figure $9 \mathrm{~b}$ ).

\section{Acknowledgements}

The authors would like to acknowledge the support provided by the Deanship of Scientific Research (DSR) at King Fahd University of Petroleum \& Minerals (KFUPM) for funding this work through Grant number IN151026.

The third author wishes to acknowledge the support given to him from the Research Grant Council of Shenzhen Government through Grant KQCX2014052114423867. The fourth author extends his appreciation to the Deanship of Scientific Research at King Saud University (Saudi Arabia) for funding part of the work through the international research group project no. IRG14-36.

\section{Appendix}

While the wavelet decomposition results of wind speed data for Al-Baha, Wadi-Al-Dawasser, KhamisMushait, Shrourah are illustrated before, those for Bishas, Madinah, Mecca, Najran, and Taif are presented in figures A1-A5.

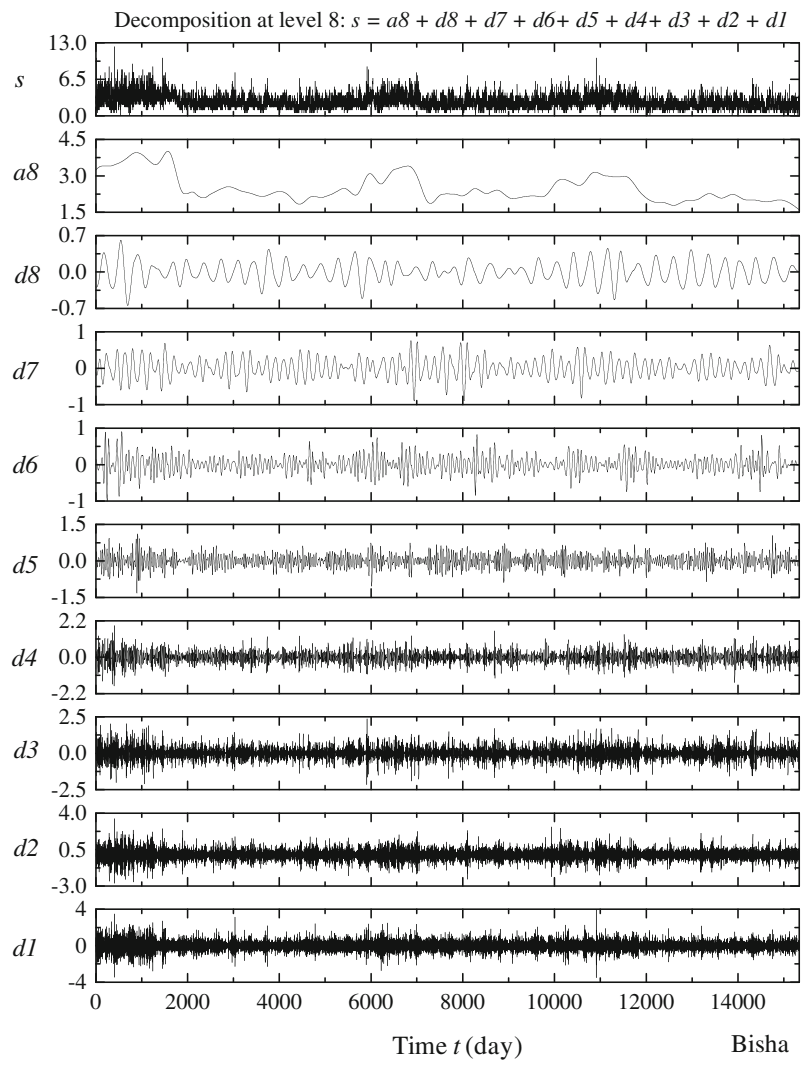

Figure A1. Decomposition of wind speed time series data for Bisha using db8.

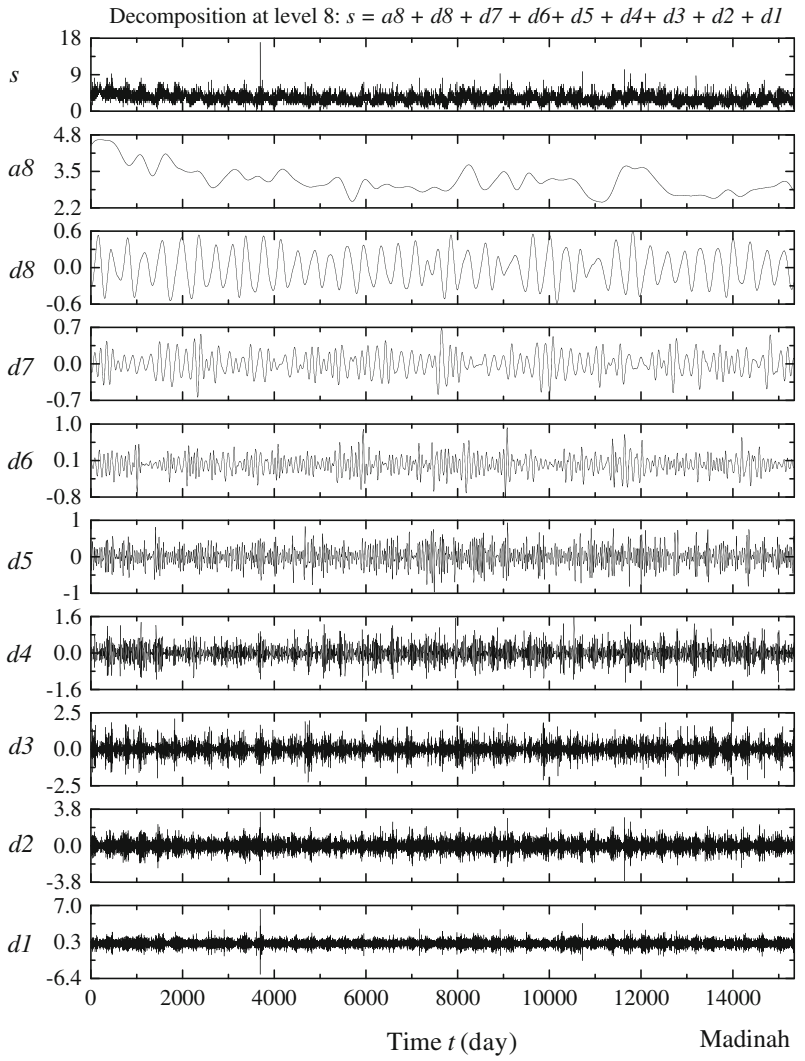

Figure A2. Decomposition of wind speed time series data for Madinah using db8.

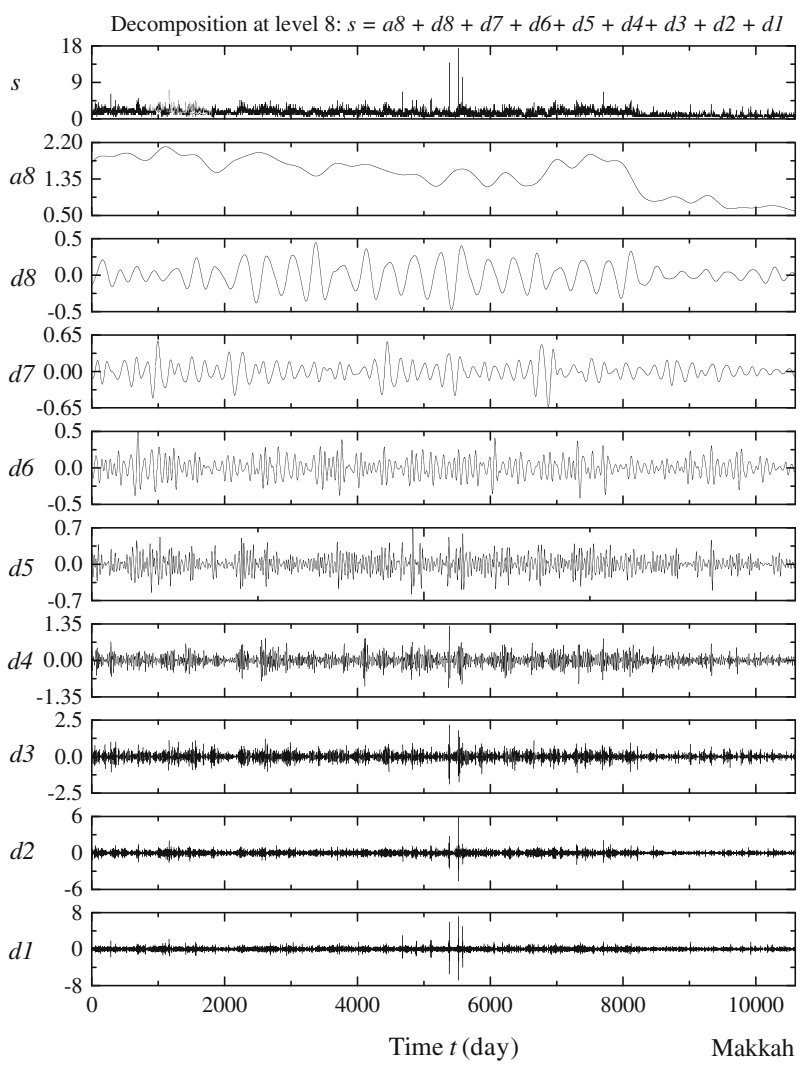

Figure A3. Decomposition of wind speed time series data for Mecca using db8. 


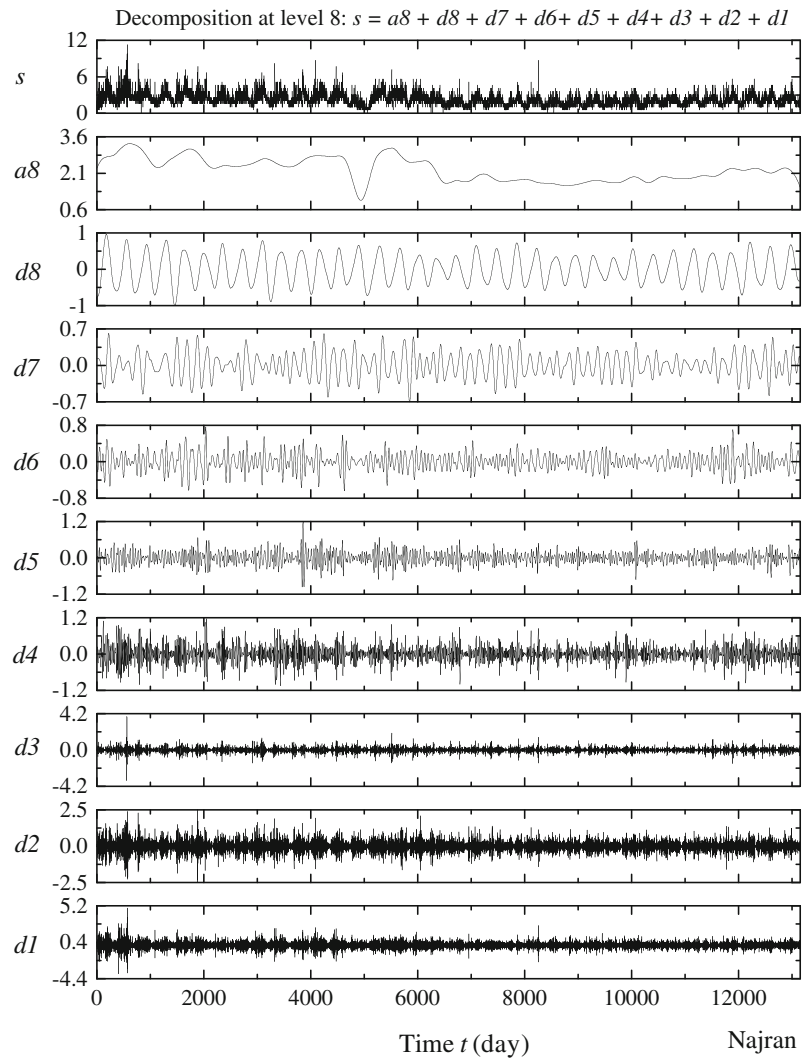

Figure A4. Decomposition of wind speed time series data for Najran using db8.

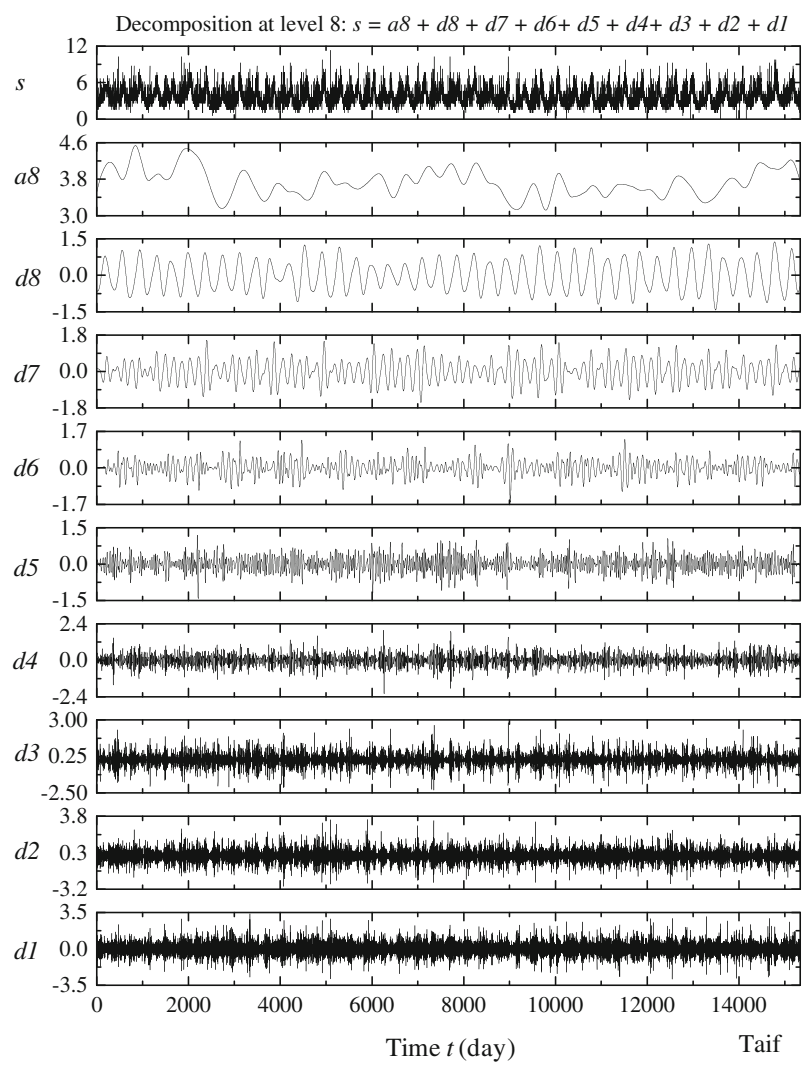

Figure A5. Decomposition of wind speed time series data for Taif using db8.

\section{References}

Akdağ S A, Bagiorgas H S and Mihalakakou G 2010 Use of two-component Weibull mixtures in the analysis of wind speed in the Eastern Mediterranean; Appl. Energy $\mathbf{8 7}$ 2566-2573.

Aksoy H, Toprak Z F, Aytek A and Unal N E 2004 Stochastic generation of hourly mean wind speed data; Renew. Energy 9 2111-2131.

Alam M M, Rehman S, Meyer J and Al-Hadhrami L M 2014 Extraction of the inherent nature of wind using wavelets; Energy Sustain. Develop. 22 34-47.

Bagiorgas H S, Mihalakakou G, Rehman S and AlHadhrami L M 2012 Offshore wind speed and wind power characteristics for ten locations in Aegean and Ionian Seas; J. Earth Syst. Sci. 121(4) 975987.

Billinton R, Chen H and Ghajar R 1996 A sequential simulation technique for adequacy evaluation of generating systems including wind energy; IEEE Trans. Energy Convers. 11 728-734.

Carapellucci R and Giordano L 2013 The effect of diurnal profile and seasonal wind regime on sizing grid-connected and off-grid wind power plants; Appl. Energy 107 364-376.

Carta J A, Ramirez P and Velazquez S 2009 A review of wind speed probability distributions used in wind energy analysis case studies in the Canary Islands; Renew. Sustain. Energy Rev. 13 933-955.

Chang T P 2011 Performance comparison of six numerical methods in estimating Weibull parameters for wind energy application; Appl. Energy 88 272282.

Chellali F, Khellaf A and Belouchrani A 2010 Wavelet spectral analysis of the temperature and wind speed data at Adrar, Algeria; Renew. Energy 35 12141219.

Deane J P, Drayton G and Gallachóir B P Ó 2014 The impact of sub-hourly modelling in power systems with significant levels of renewable generation; Appl. Energy $113152-158$.

Garcia-Marin A P, Estevez J, Jimenzez-Hornero F J and Ayuso-Munioz J L 2013 Multifractal analysis of validated wind speed time series; Chaos, Non-Linear Sci. $\mathbf{2 3}$ 013133.

Georgilakis P S 2008 Technical challenges associated with the integration of wind power into power systems; $J$. Earth Syst. Sci. 12 852-863.

Global Wind Energy Council (GWEC) annual report 2015 http://www.gwec.net/wp-cont/uploads/2012/06/ GLOBAL_INSTALLED_WIND_POWER_CAPACITY_ MW_-_Regional_Distribution.jpg.

Jaramillo O A and Borja M A 2004 Wind speed analysis in La Ventosa, Mexico: A bimodal probability distribution case; Renew. Energy 29 1613-1630.

Kumar V S and Philip C S 2010 Variations in long term wind speed during different decades in Arabian Sea and Bay of Bengal; J. Earth Syst. Sci. 119(5) 639653.

Rehman S, Alam M M, Meyer J P and Al-Hadhrami L M 2012 Wind speed characteristics and resource assessment using weibull parameter; Int. J. Green Energy 9(8) 800-814. 
Rehman S, Al-Hadhrami L M and Alam M M 2015 Pumped hydro-energy storage system: A technological review; $J$. Earth Syst. Sci. 44 586-598.
Smith J C, Milligan M R, DeMeo E A and Parsons B 2007 Utility wind integration and operating impact state of the art; IEEE Trans. Power Syst. 22 900-908.

MS received 12 May 2016; revised 23 December 2016; accepted 25 December 2016

Corresponding editor: KAVIRAJAN RAJENDRAN 